\title{
CHILLIDA DESDE HEIDEGGER: A montanha de Tindaya ou o elogio do inútil ${ }^{1}$
}

\author{
CHILLID A FROM HEIDEGGER: The Mountain of Tindaya or the eulogy of the useless
}

Oscar Federico Bauchwitz ${ }^{2}$

\section{http://dx.doi.org/10.52641/cadcaj.v6i4.468}

RESUMO: Análise do projeto Montanha de Tindaya do escultor Eduardo Chillida, a partir do pensamento de Martin Heidegger. Propõe-se uma perspectiva de interpretação que considera a exortação do sentido do inútil como pensamento e a obra de Chillida como plasticidade deste sentido.

Palavras-Chave: Arquitetura Heterodoxa; Topologia do ser; Espaço

ABASTRACT: Analysis of the Tindaya Mountain project by the sculptor Eduardo Chillida, from the thought of Martin Heidegger. It is proposed a perspective of interpretation that considers the exhortation of the meaning of the useless as thought and the work of Chillida as plasticity of this sense.

Key-Words: Heterodox Architecture; Topology of Being; Space.

\section{INTRODUÇÃO}

Já foi dito que Martin Heidegger e Eduardo Chillida compartilham e expressam concepções teóricas semelhantes entre si, de forma escrita o primeiro, plasticamente o segundo, como se a obra do basco fosse um paralelo artístico do pensador alemão. ${ }^{3}$ Essa suposta semelhança, se exprimível, não se deve à influência do pensamento do alemão junto ao artista basco, nem mesmo a um insight que a obra de arte poderia ter suscitado ao filósofo, senão ao fato de ambos coincidirem em entender que suas obras e seus respectivos ofícios são, essencialmente, questionamentos acerca do espaço.

Com o título Chillida desde Heidegger se expressa a aproximação da obra chillidiana do pensamento heideggeriano, mediante a análise de uma obra que a dia de hoje ainda não veio à luz, um projeto não realizado entendido como uma afronta às concepções ambientalistas que veem na sua execução mais uma violência sem justificativa e uma manipulação desmedida de uma

\footnotetext{
${ }^{1}$ Este trabalho foi desenvolvido com o apoio do Programa Institucionall de Internacionalização (PRINT -

CAPES/UFRN), junto à Universidad de Sevilla, na modalidade de Professor Visitante no Exterior (2019-2020).

2 Professor Titular de Filosofia da UFRN, Docente do PPGFIL UFRN

3 Mais que um influxo do pensamento de Heidegger na concepção criativa de Chillida, deveria pensar-se em "influencias reciprocas o simplemente de concomitancias entre concepciones teóricas escritas y concepciones teóricas plasmadas plásticamente" (BARAÑANO, 1990, p.123). Nessa perspectiva, a obra de Chillida seria um visual thought, (BARAÑANO, 1999, p.19). Também Fath indica esta relação: "(la obra de Chillida) constituye un paralelo artístico del pensamiento de un filósofo notable" (FATH, 1990, p.109).
} 
região e de um espaço natural: a Montanha de Tindaya situada na ilha canária de Fuerteventura. ${ }^{4}$ Procura-se alcançar uma perspectiva que, à semelhança do que ocorre com as obras produzidas por Chillida, que exigem ser apreciadas por diferentes ângulos, obrigando o espectador a perambular e a observar detidamente o que elas guardam dentro de si e irrompe ao seu redor, como também, em alguns casos, exigem que o espectador entre completamente em seu espaço interior; de modo semelhante, também Heidegger demanda um deslocamento para além da compreensão habitual que se tem das coisas. Daí o porquê do nosso título, A Montanha de Tindaya on o Elogio do inútil. Uma perspectiva pela qual a obra pensada durante décadas por Chillida corresponderia essencialmente ao pensamento de Heidegger como um questionamento que suscita uma reflexão sobre o espaço que não se reduz a uma concepção sobre o sentido da arte, mas também faz pensar sobre as possibilidades do ser humano habitar e construir, participando daquilo que Heidegger chamou de poetizar pensante (denkende Dichten), e, portanto, capaz de promover uma topologia do ser, quer dizer, capaz de dar lugar ao ser (1983A, p. 84).

A relação entre o pensador e o artista foi objeto de estudos ao longo das últimas décadas, muito por conta do interesse que despertou o ensaio $A$ arte e o espaço (1969) de Heidegger, ilustrado por litocollages especialmente criadas por Chillida para a publicação e que demandou de ambos uma peculiar colaboração. ${ }^{5}$ Trata-se de um texto fundamental ao propósito de pensar uma ontologia da arte e uma estética na obra de Heidegger. No começo dessa obra, Heidegger explicita que "as observações sobre a arte, o espaço e o jogo recíproco entre ambos não deixam de ser perguntas, por mais que se expressem em forma de afirmações” (HEIDEGGER, 1983B, p.204), coincidindo com a reflexão do artista basco que afirma que "todas as obras são em realidade interrogantes, perguntas" (CHILLIDA, S. 2003, p.16). Por diferentes meios, o pensador e o artista partilham uma mesma procura determinada pelo exercício do pensamento e por um agir que guardam sentido e lugar ao desconhecido, sem a ânsia de um saber fazer que a tudo arregimente e o torne disponível.

\section{HEIDEGGER E O INÚTIL}

Pertence à filosofia um questionar próprio e originário que não só envolve o que é questionado, mas também repercute no próprio ato de questionar e, portanto, naquele que

\footnotetext{
${ }^{4}$ As críticas à execução do projeto apontam que, além de desfigurar o perfil da montanha, Tindaya é um lugar sagrado, que possui pinturas rupestres, que o trânsito de veículos e visitantes traria consequências perturbadoras ao meio ambiente. A julgar por algumas das entrevistas que concedeu e pelos seus comentários, não parece que Chillida tenha negligenciado esses problemas. Para uma visão geral das críticas veja-se https://www.salvartindaya.org

$5 A$ arte e o espaço está dedicado a Eduardo Chillida. Trata-se, originalmente, de um livro especial de edição numerada e que exigiu de Heidegger escrever diretamente sobre a pedra, de tal modo que o livro é quase, por assim dizer com um acentuado sabor heideggeriano, um negativo do positivo.
} 
questiona. A filosofia é um questionar extraordinário porque não busca constituir-se como um saber que serve ao planejamento, ao controle ou que possa contabilizar resultados que referendem a sua serventia. Tais possibilidades pertencem ao pensamento calculador e não servem de medida senão para si mesmo. O questionar propriamente filosófico, e não só o seu “objeto”, é sempre extraordinário (HEIDEGGER, 1983C, p.15). Esse caráter de encontrar-se deslocada e inapropriada às ocupações do mundo acaba por deixar a filosofia em uma situação vulnerável: pelo simples fato da filosofia não se disponibilizar como um saber pragmático sempre à mão, como um dispositivo a ser acionado quando necessário, sempre pode sofrer a interdição daqueles que pensam que agir deve trazer algo de efetivo ao ritmo ordenado do cotidiano, algo que contribua com a realização do ser humano e que lhe permita afiançar a sua existência em um mundo que lhe seja familiar e seguro. Nesse mundo, destinado a suprir as necessidades, vigoram processos e procedimentos que "provavelmente deslocarão o pensar meditativo como coisa inútil e do qual cabe por isso prescindir" (HEIDEGGER, 1997, p.22). Como consequência do seu deslocamento, o sentido extraordinário da filosofia não permite ser valorado pelas medidas que regem e agenciam demais saberes e ocupações que se dirigem pela busca do útil e pela imediata resposta às necessidades que assolam o ser humano em seu mundo. No entanto, se insistimos na procura extraordinária da filosofia, então deveríamos aprender que a filosofia, sendo propriamente inútil, é algo do qual o ser humano não pode prescindir, a menos que nesse processo ele mesmo, absorvido em seu mundo, tenha deixado de pensar. Nessa insistência, no manter-se nesse lugar e a partir dele, dá-se uma estranha experiência na qual todas as coisas se reúnem e permanecem serenas em sua própria liberdade, alheias a toda utilidade previamente determinada.

Em que pesem os prodigiosos resultados do pensamento calculador, afirma Heidegger que "meditar é despertar o sentido do inútil” (1989, p.6), evitando que o ser humano permaneça preso a uma compreensão utilitarista que, ao tempo que promove a instauração do útil por toda parte, inviabiliza e interdita toda experiência alheia ao seu domínio. O pensamento só pode ter lugar fora desse domínio e, portanto, deve ter algo a ver com o inútil e com a experiência inabitual que permite percebê-lo. A promoção dessa experiência, a percepção desse estranho lugar onde vigora o inútil é algo destinado ao pensamento e ao seu questionar e, como supomos aqui, também à obra de arte e, em especial, a de Chillida.

\section{O PENSADOR E O ARTISTA}

Uma olhada na obra de Eduardo Chillida permite ver a proximidade do artista respeito às reflexões que Heidegger desenvolve acerca da obra de arte e a escultura, do espaço e lugar, do 
construir e habitar. Esta proximidade, no entanto, não pode ser vista como uma consequência da relação que ambos mantiveram na realização de $A$ Arte e o Espaço. ${ }^{6} \mathrm{O}$ que é fundamental nessa proximidade é, para Chillida, a ideia do espaço insondável que Heidegger investiga, "aquela extensão uniforme, aonde nenhuma das posições possíveis é privilegiada, válido em qualquer direção, mas imperceptível aos sentidos” (HEIDEGGER, 1983B, p.204). O espaço inominável que se apresenta de um estranho modo desde a ubiquidade de sua presença.

A obra de Chillida, como reconhece o artista, é um questionamento pelo espaço, pelo espaço da obra e pelo próprio modo do ser humano, o mistério absoluto que nos constitui. Alçado à condição de mistério, o espaço é o próprio cerne de sua criação. Diz Chillida: “O espaço será anônimo enquanto não o limite. Antes minhas obras eram protagonistas, agora devem ser meios para fazer protagonista ao espaço e que este deixe de ser anônimo" (CHILLIDA, 2005, p.58). A obra como meio, como lugar onde o próprio espaço irrompe do anonimato. Já como escultor, Chillida está "condicionado pelo espaço” (CHILLIDA, 2003, pp.29-30), ${ }^{7}$ deve saber do espaço para orientar o seu fazer artístico, uma vez que "onde o espaço não atua, não há escultura" (VALENTE/ CALVO SERRALLER, 1996, p. 107). As suas obras se constituem como a repetição de uma única questão, cada uma delas se apresenta como uma possibilidade e um modo de confrontar-se com o próprio espaço:

Quero ir encerrando o espaço em minha obra. O espaço perfeito é oculto, devo chegar a ele por etapas. Minhas obras atuais serão as que possam explicar as futuras, uma vez que estas podem chegar a ser herméticas, que dizer, a ocultar seu coração, seu motivo ou sua força, e isto por pura física, não por outras razões (CHILLIDA, 2005, p.59).

Considerando a indicação do artista de que as suas obras já realizadas podem explicar as que estão por vir e que, desde a perspectiva assumida pelo artista, o seu empenho é uma busca pelo espaço para trazê-lo à obra e encerrá-lo gradualmente, então, deveríamos encontrar uma série de obras que colaborem na compreensão da Montanba de Tindaya porque expressam a concepção fundamental que subjaz ao projeto, permitindo visualizar, em diferentes escalas e materiais, o anseio por dar e construir um lugar para o espaço, propiciando uma experiência espacial através da qual o próprio espaço se mostre para além dos lugares em que se habita. Assim entendida, a

\footnotetext{
${ }^{6}$ Tendo como base a cronologia de Esteban (1971, p.185), Groth entende que as observações de Chillida foram escritas “independentemente da familiaridade de primeira mão com o pensamento de Heidegger” (2018, p.295). Chillida afirma: "para mí fue una sorpresa encontrar en la preocupación del filósofo alemán algunos puntos que para mí eran vitales y estaban encarnados en mi obra" (UGALDE, 2002, p. 100). Por outra parte, os nomes de suas obras dão testemunho do interesse do artista pelo espaço e seus correlatos: Ao redor do vaz̧io; Procurando lugar, Lugar de Encontro, Conselho ao Espaço e ao Tempo, Rumor de limites, Modulação do Espaço, Elogio do Horizonte, Topos, Casa de Bach, A Casa de Hokusai, A Casa de Goethe, etc.

${ }^{7}$ Chillida conta que perguntou a Heidegger pelo tamanho de papel que o alemão havia utilizado com mais frequência em seus escritos. A pergunta surpreendeu o alemão, mas se justificava pela ocupação do artista: "soy escultor, y estoy muy condicionado por el espacio". A resposta de Heidegger determinou o tamanho do livro.
} 
obra é o lugar aonde o espaço vem à luz e se deixa ver enquanto espaço. Mas o que é o espaço e de que modo ele se mostra são questões às quais o escultor se dedicou mais em plasticizar do que propriamente em responder em seus escritos. Para Chillida, suas obras são elas mesmas questionamentos e comportam um problema em comum: "o espaço interior, consequência e origem ao mesmo tempo dos volumes positivos exteriores. Para definir estes espaços é necessário rodeá-los, tornando-os inacessíveis para o espectador situado no exterior" (CHILLIDA, 2005, p.52). Os volumes exteriores, a obra criada à qual temos acesso em maior ou menor medida, guardam dentro de si um espaço de outra natureza, um espaço que atua sempre de modo mais ativo quanto mais oculto permanece. Há uma correlação e um diálogo entre esses espaços e no caso do escultor, isso significa a promoção de uma espécie de jogo entre a concretude da matéria e o espaço que Chillida chamou da dialética do cheio-vazio: "Incidindo no espaço com a matéria. Incidindo na matéria com o espaço” (p.54). A obra se converte em um guia seguro para chegar a conhecer "ao menos em seu espírito, a estes espaços ocultos" (p.52).

Considerando que Chillida entende as suas obras como questionamentos sobre o espaço, podemos dizer que esses questionamentos encontram ressonância em $A$ arte e o espaço. Para Heidegger a análise da escultura ou figura plástica parte da questão fundamental do espaço. A escultura se relaciona com o espaço artístico com base em uma configuração da matéria e a partir do jogo delimitador que inclui e exclui a partir de um limite. Ela tem corpo e ocupa um espaço e Heidegger se pergunta de que modo ela incorpora o espaço para si:

é uma apropriação, um assenhoramento do espaço? Corresponde a arte plástica à conquista técnico-científica do espaço? Não persegue também a escultura este desafio, na medida em que ela é entendida enquanto um confrontar-se com o espaço? Ela não se encontra confirmada nesse seu caráter moderno? (HEIDEGGER, 1983B, p.204).

Ao questionar se a arte e a técnica-científica são provocadas pelo mesmo desafio, Heidegger abre caminho para uma reflexão que acaba por evidenciar que a arte se relaciona com o espaço de um modo próprio, sem acatar as diretrizes modernas de um espaço “objetivo e verdadeiro", regido pelos valores calculáveis do pensamento técnico-cientifico. Nessa relação, no acontecimento da obra, tem-se uma experiência de caráter extraordinário que permite ver algo de próprio do modo do ser humano. Isso, talvez, não possa ser dito acerca de toda obra de arte, mas é na escultura onde tem lugar a emergência do sentido essencial do espaço e não só de um espaço artístico.

Reconhece Heidegger que "a pergunta pelo que é o espaço enquanto espaço ainda não foi perguntada, quanto menos ainda respondida. Permanece não decidido de que modo o espaço é e, sobretudo, se a ele um Ser pode ser concedido” (1983B, p. 205). Para avançar nessa investigação 
sobre o espaço que arte é capaz de plasticizar, torna-se necessário, primeiramente, investigar o que é o espaço. Na ressonância que ecoa na palavra espaço (Raum), diz Heidegger, fala o espaçar (Räumen), roçar, preparar um roçado, abrir um claro na mata. Daí que espaçar significa fornecer o livre, a abertura que propicia o habitar do homem: "Espaçar é, propriamente, doação de lugares", o essencial desse acontecimento que é o espaçar dá-se no "arrumar" (einräumen) que

faz prevalecer o aberto no qual se dá a aparição das coisas às quais se remete o habitar do homem. Por outro lado, o arrumar é também um dispor que proporciona às coisas a possibilidade de se pertencerem mutuamente desde os seus respectivos lugares de onde se abrem às demais (p.207).

O lugar arrumado, próprio do espaçar, abre, a cada vez, uma região (Gegend), uma paragem que reúne dentro dela as coisas em mútuo pertencimento. Reunir, por sua vez, significa um albergar que deixa as coisas serem livres em sua região. Parece desvendar-se a peculiaridade do espaço. Os lugares não são somente uma consequência do arrumar, mas o arrumar recebe o que lhe é próprio dessas reuniões-lugares. ${ }^{8} \mathrm{O}$ espaçar enquanto arrumar diz "fundação de localidade" e a localidade o "jogo mútuo de lugares", mediante o qual as coisas se relacionam entre si e coexistem. Conclui Heidegger que "deveríamos aprender a reconhecer que as coisas são em si mesmas lugares e não apenas pertencem a um lugar"' (1983B, p.208).

Uma vez encontrada a peculiaridade do espaço, resta considerar de que forma a arte se relaciona com o espaço. Surge, então, uma interpretação já indicada no começo do ensaio de Heidegger: "a arte como plástica (escultura): nenhuma apropriação e dominação do espaço" (Idem), nela deixa-se ver o sentido do espaço. A obra "incorpora" ou "corporifica" lugares que "acolhendo e guardando uma região, mantém reunido ao seu redor a liberdade que confere às coisas uma permanência e aos homens um habitar em meio às coisas” (Ibidem). A obra dá "corpo" à verdade do ser na medida em que promove uma abertura onde o próprio espaço se deixa ver. A escultura dá lugar, plasticamente, ao próprio espaço que nela opera. A escultura é o lugar do espaço enquanto espaço, quer dizer, ela provoca no espectador uma experiência concreta e inabitual do espaço. Com e por ela, abre-se um lugar que não se encontra determinado pelas ocupações cotidianas, senão que demanda certa des-ocupação, um deixar-ser e, em consequência, a descoberta que dentre as possibilidades de estar em seu mundo e de construí-lo, de lidar com coisas e produzi-las, está aquela que vigora desde o próprio livre e evidencia que a existência humana é decisiva para que as coisas sejam o que são.

\footnotetext{
8 Veja-se a análise que Heidegger faz de uma ponte como reunião integradora em Construir, Habitar, Pensar (HEIDEGGER, 2000, pp.154ss).
} 
Entretanto, o que significa deixar a coisa ser o que é? Nada parece mais fácil que deixar o ente ser o que é, diz Heidegger e, no entanto, isso é o mais dificultoso. Tomada por todo tipo de premências, a existência humana pouco experimentada nesse deixar-ser, acaba considerando tratar-se de um "deixar pra lá” ou de uma ação que nada pode promover de útil; mas o que se revela nesse deixar-ser é que as coisas ganham sentido e lugar. Em função destes o ser humano se afiança junto ao seu mundo. O projeto de Chillida surge, então, como explicitação de um deixarser, propiciando um exemplo concreto e essencial acerca do construir, incluído aí o fazer artístico.

\section{CHILLIDA E O ELOGIO DO INÚTIL}

A Montanba de Tindaya, "a obra mais conceitual e mais arquitetônica" de Chillida (BARAÑANO, 1998, p.57), além de ter suscitado uma confrontação com o ambientalismo, também despertou o debate para saber até que ponto ainda se trataria de uma obra escultórica ou se não seria o caso de reconhecer tratar-se de um projeto muito mais próximo da arquitetura. Tal debate, como soe acontecer, não encontra um consenso. Por um lado, o projeto culmina a trajetória criadora de Chillida e expressa com veemência as inquietações e a procura do artista; mas por outro lado, se poderia objetar que tal projeto, paradoxalmente, converteria o escultor em arquiteto ou que, ao menos, desde o seu fazer artístico, Chillida promove uma reflexão sobre o sentido da própria arquitetura, aparentemente destinada a criar lugares funcionais e úteis para a cotidiana existência humana. ${ }^{9}$ Seria temeridade ou insensatez pensar que a arquitetura só se mostrará abdicando do seu compromisso com a funcionalidade e o caráter útil do construir ou seria possível, e talvez até mesmo recomendado, pensar em uma arquitetura do inútil?. ${ }^{10}$

O projeto de Tindaya procura criar um lugar que permita igualar a todos os homens diante da imensidão do espaço logrado, é uma homenagem à humanidade:

\footnotetext{
9 Pinilla reconhece a relevância da obra de Chillida em suscitar uma reflexão sobre a "índole da arquitetura" e sobre as diferenças próprias entre o escultor e o arquiteto. Por outro lado, a própria ideia de funcionalidade como característica fundamental do arquitetônico não pode significar uma necessária renúncia a construir lugares cuja função não seja tão explicitamente útil como, por exemplo, uma igreja, um jardim, um pátio, onde também pode se dar uma reflexão e uma experiência do lugar, tanto como acontece com a obra chillidiana (PINILLA, 2002, pp.269271). Barañano, por sua vez, analisando a reforma que o artista faz da casona de Zabalaga, presente em Chillida-Leku, considera que Chillida promove uma arquitetura heterodoxa, "o seu interior deixa de ser arquitetura (de construir para habitar) para ser espaço de escultura (âmbito para pensar e para sentir nosso lugar)" (1998, p. 57). Nesse sentido, Algarín Comino entende que Chillida contribui para enfraquecer a fronteira que separa a escultura da arquitetura, de forma que a arquitetura livre, aquela que alcançou a liberdade, como já pensava Ozenfant, é escultura (2006, p.273). Mattos Castaño reconhece que, "su escultura puede ser el germen de muchas arquitecturas" (2015, p.9).

${ }^{10}$ Como se supõe a partir do arquiteto alemão Bruno Taut: "(a arquitetura) assume um papel modesto na existência humana, o papel de uma 'arte útil' que satisfaz as necessidades práticas de uma forma agradável. Somente quando os desejos humanos superam a satisfação das necessidades básicas, quando se alcança o excedente do bem-estar que o luxo reclama, a arquitetura parece que se faz mais presente e mostra seu eu com maior intensidade. Então, não parece tão estritamente ligada à necessidade, daí que possa ser verdadeiramente contemplada como arte" (1997, p.37).
}

Cadernos Cajuína, V. 6, N. 1, 2021, p. 326-338. 
Ofereço esta obra a todos os homens, de todas as raças, de todas as cores, de todas as tendências. É por isso que a obra requer certa dimensão, porque quanto mais nos sintamos pequenos em um espaço grande, mais iguais nos sentiremos (CHILLIDA, S., 2003, p.59).

Trata-se de uma obra monumental - 50x50x50 metros - cujas dimensões, como gostava de lembrar Chillida, ${ }^{11}$ permitiriam abrigar o Panteão de Roma. Um grande espaço no interior da montanha com duas amplas entradas verticais de luz e uma abertura de acesso ao recinto (Figuras 1, 2, 3 e 7). O cerne de sua concepção está presente em diversas obras que o artista produziu ao longo de décadas e a partir desses precedentes podemos intuir o que se propõe para Tindaya. Chillida descreve a sua criação de modo a explicitar a conjunção que a obra propicia entre céu e terra, exterior e interior:

Não tem mais que três comunicações com o exterior, duas que vão procurando a luz acima, a luz do sol e da lua, e, por outro lado, o mar, o mar e o oeste. Dá para o oeste e para o horizonte inalcançável, necessário e inexistente, que está ali como sempre à beira do olhar de todos os homens (CHILLIDA, S. 2003, p.110).

Figura 1

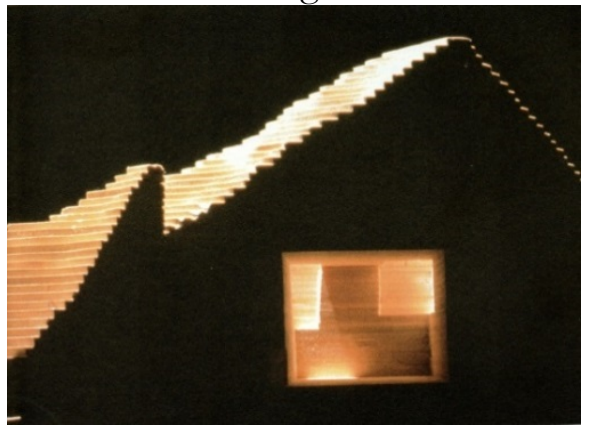

Fonte: www.estudioguadiana.com
Figura 2

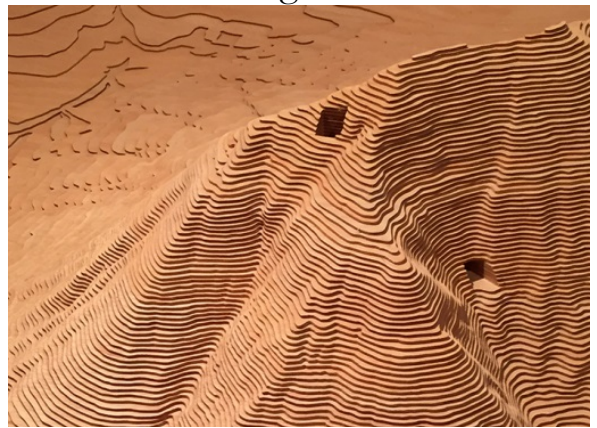

Fonte: www.salvartindaya.org

Figura 3

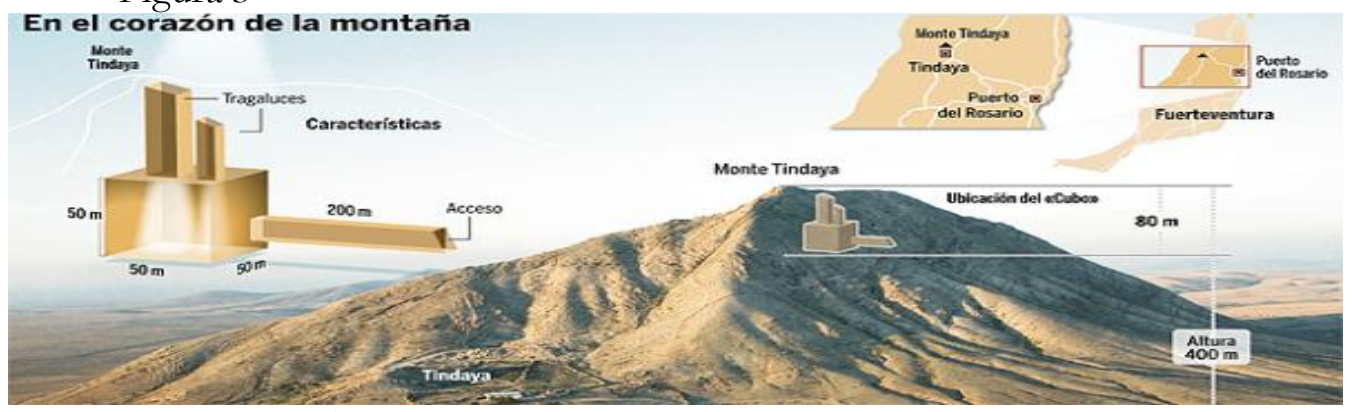

Fonte: La rąón, Las Palmas (28.01.2011)

Aceitando-se que as ideias que orientam o projeto de Tindaya devem de haver estado presentes na concepção das obras realizadas, ${ }^{12}$ é razoável pensar que observando algumas dessas obras

11 VALENTE / CALVO SERRALLER, 1996, p. 111; CHILLIDA, S., 2003, p.168.

${ }^{12}$ Chillida comenta que o projeto de Tindaya se gestou durante décadas e que muitas de suas obras são experiências da concepção fundamental que o guia; menciona o alabastro de sugestivo nome Mendi-Uts I (1984), "A montanha vazia" e o Elogio del Horizonte. A estas podem somar-se as séries de Elogio de la Arquitectura I-XV (1968-1996), 
poderíamos alcançar uma compreensão que o resguardasse das criticas que o invalidam atualmente. Considerando a vasta produção do escultor, são muitas as obras que poderiam colaborar na compreensão do projeto de Tindaya. Vejamos, ao menos, duas que surgem como referências necessárias e são apontadas pelo artista. A primeira delas é o emblemático Elogio del Horizonte (1990, Figura 4). Uma estrutura de concreto armado, construído sobre o mar em uma colina da cidade de Gijón. Na visão do artista, a obra promove uma experiência fundamental sobre o sentido do horizonte, evidenciando que o seu caráter sempre fugidio e de retração, ao tempo que sua ubiquidade e manifestação indicam que o horizonte é a pátria de todos os homens (CHILLIDA, S. 2003, p.168). O espaçar da obra, quer dizer, a irrupção do lugar da própria obra, acolhe e concede medida àqueles que perambulam ao seu redor e a observam. Abre-se um horizonte a partir do qual todas as coisas se visualizam e se situam a partir de uma distância que nada tem a ver com uma ou outra medida tridimensional. Na concepção do artista, a terra se mostra como o horizonte necessário e comum a todos os homens: "Entendi o que é o horizonte, melhor do que geralmente se entende. Algo que não existe, que é necessário, que é inalcançável, mas que é muito importante" (2005, p.87).

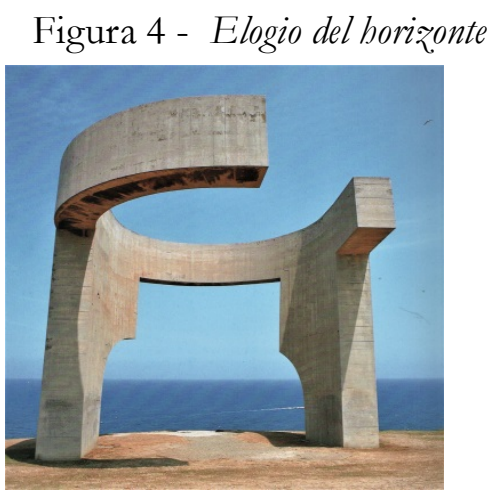

Fonte:Chillida, 2006.

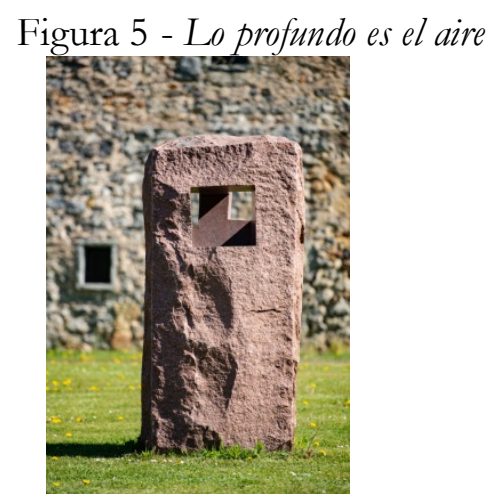

Fonte: $\underline{\text { arquitecturaviva.com }}$

A segunda obra, Lo profundo es el aire XII (1990, Figura 5 e 6) que homenageia o poeta Jorge Guillén, cujos versos dão nome a uma longa série de trabalhos. Trata-se de um granito com aberturas em suas esquinas que permitem a entrada da luz. Chillida entende que esta obra "poderia ser o modelo adequado para a intervenção na montanha". ${ }^{13}$ Uma espécie de anteprojeto de Tindaya (MATOS CASTAÑO, 2015, p.300), que permite intuir, ainda que em menor escala, o espaço interior, aquele vazio conquistado junto à matéria. Nas palavras de Matos Castaño, o "espaço vigente nessa obra é o espaço interior de Tindaya".

Homenaje a la Arquitectura I-(1973), Arquitectura Heterodoxa I-V (1974-2000), Homenaje a Goethe I-V (1975-1979), Lo profundo es el aire I-XXI (1983-1998).

${ }^{13}$ Entrevista a Ángeles Alemán, Diario de Las Palmas, 03.07.1995, (MATOS CASTAÑO, 2015, p.300). 
Figura 6 - Lo profundo es el aire XII

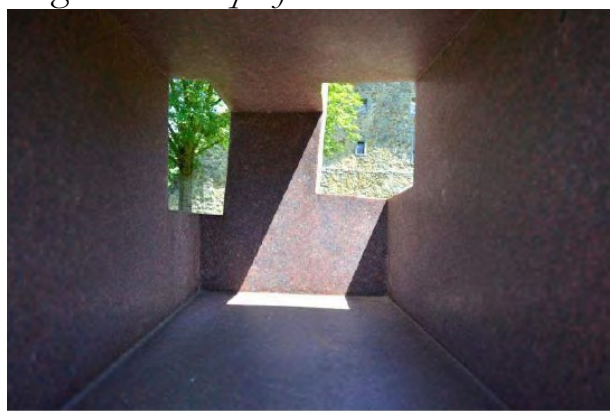

Fonte: Matos Castaño, 2015
Figura 7 - Montanha de Tindaya

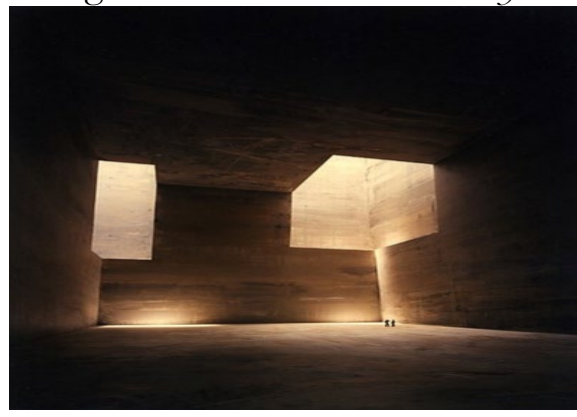

Fonte: www.estudioguadiana.com

Uma passagem de $A$ origem da obra de arte, onde Heidegger, partindo da sua concepção da arte como um deixar ver o confronto entre mundo e terra, põe um pouco mais de luz sobre a obra chillidiana:

Para onde a obra se retira e o que ela faz ressair nesse retirar-se, eis o que chamamos terra (Erde). Ela é o que ressai e dá guarida. A terra é o infatigável e incansável que está ai para nada. $\mathrm{Na}$ e sobre a terra, o homem histórico funda seu habitar no mundo. $\mathrm{Na}$ medida em que a obra instala um mundo, produz a terra. [...] A obra move a própria terra para o aberto de um mundo e nele a mantém, a obra deixa que a terra seja terra (1977, p.32).

Enquanto obra de arte, Tindaya abre um lugar que deixa ver, traz à luz a emergência da terra. E isso não porque leve luz ao seu interior, senão porque o interior da montanha vem à luz resguardado em seu próprio ocultamento. ${ }^{14}$ A obra abriga e deixa ver o sentido próprio da terra como doação inobjectual aquém da apropriação e do uso da mesma desde a perspectiva da utilidade e da confiança que concedem ao homem a possibilidade do mundo. A obra de Chillida indica um deixar-ser, um agir humano que sustenta a possibilidade de que algo seja. Um agir estranho porque não possui - e nem deseja possuir - diretrizes ou resultados que possam ser calculados. Trata-se de um agir que corresponde ao que foi dito sobre a reunião integradora dos lugares como a sustentação do livre. O esvaziamento da montanha corresponde ao lugar criado em seu interior, um grande vazio introduzido no coração da montanha (VALENTE/ CALVO SERRALLER, p. 110). Demanda a precisão e o uso de ferramentas e tecnologias avançadas que zelem pelo perfil da montanha, ${ }^{15}$ mas é aqui que se manifesta a diferença fundamental do fazer técnico para o artístico: não se procura explorar a montanha tirando proveito de suas reservas ocultas, não se trata de torná-la útil para suprir uma necessidade; não se quer gastar a montanha como quem desgasta a lâmina de um machado, mas sim de nela encontrar morada. Trata-se de despertar o sentido do inútil - o estar-aí para nada - da terra, deixando que seja terra, antes de

\footnotetext{
14 Veja-se o estudo significativo sobre este tema no conjunto da obra chillidiana de RABE, 2003, pp. 169-191.

15 Para um detalhamento técnico das etapas da construção e os protocolos de controle para a preservação da montanha e do entorno, veja-se MATOS CASTAÑO, 2015, pp. 319-324.
} 
converter-se em objeto da exploração humana. A obra daria acesso ao interior da montanha, associando de vez e de modo irrevogável o homem e a terra, deixando ver que o homem pertence ao mistério da terra. Como escreveu José Angel Valente, o poeta e ensaísta espanhol, a montanha de Chillida está tomada pela missão poética de "criar o lugar de uma possível epifania, e isso seria provocar a natureza em sua intimidade, torná-la um lugar propício à manifestação, à epifania” (VALENTE/CALVO SERRALLER, idem).

\section{CONCLUSÃO}

Heidegger descreve um encontro que teve com Ortega y Gasset por ocasião do Congresso de Darmstadt, em 1951.. ${ }^{16}$ Recorda que após concluir a leitura de sua conferência Construir, Habitar, Pensar, sofreu duros ataques de um dos assistentes, e o filósofo espanhol saiu em sua defesa argumentando que o pensamento do alemão, que naquele momento resultava ser de difícil compreensão, quando não inoportuno frente aos desafios impostos por uma Europa devastada pela guerra, era um pensamento necessário. Esses ataques consideravam a reflexão de Heidegger como um pensamento alheio às necessidades prementes do reconstruir, imiscuindo-se em questões que não diziam respeito à Filosofia e que acabava por destruir e reduzir à nada as inquietações e os anseios da sociedade e dos arquitetos ali reunidos. Ortega rebateu as críticas dizendo que "às vezes o bom deus precisa de um despensador (Zerdenker) para impedir que os demais animais adormeçam".. ${ }^{17} \mathrm{O}$ pensador des-pensando destrói a compreensão usual e nos desperta para um sentido que não se esgota em uma maior ou menor serventia diante do mundo. O anedótico da conferência de Darmstadt revela como o pensamento filosófico pode, aos olhos do pensamento técnico especializado, ser considerado um intruso.

$\mathrm{O}$ argumento em defesa da realização de Tindaya, em que pesem as objeções levantadas pelos movimentos ambientalistas, corresponde a um pensamento pautado pelo respeito à inviolabilidade do possível. Esvaziar uma montanha não corresponde à repetição da conduta furiosa do mundo técnico que visa a instauração do útil por toda parte, senão que denota a possibilidade de um agir guiado pelo sentido do inútil. A Montanha de Tindaya corresponde a uma conduta livre e serena que detém o poder de instaurar lugares onde o inútil conquiste reflexão e plasticidade. Ao ser um desses lugares, o projeto de Tindaya cumpre à perfeição o sentido da obra chillidiana: a obra se mostra como questão.

\footnotetext{
${ }^{16}$ HEIDEGGER, Martin. Begegnungen mit Ortega y Gasset. In Aus der Erfahrung des Denkens, 1983A, p.127ss. ${ }^{17}$ José Ortega y Gasset relata o episódio e observa que o filósofo costuma suscitar uma reação de antipatia quando o que ele diz parece invadir um domínio específico, neste caso o da arquitetura. Ver: Sobre el especialista y el filósofo (1983, pp. 628-630).
} 
A obra questiona pelo sentido da terra e descobre no inútil uma experiência possível e libertadora. O pensamento e a arte, neste caso a obra de Chillida, zelam e nos mantém despertos para este sentido. $\mathrm{Na}$ medida em que Heidegger des-pensa, Chillida, des-ocupa o espaço.. ${ }^{18} \mathrm{O}$ pensador e o artista cuidam que este sentido não caia, como é habitual, no esquecimento, abrindo lugares onde este inútil ressaia do seu ocultamento, concedendo localidade àquilo que sempre de novo insiste em se ocultar. Criar limites é criar lugares. A obra chillidiana cria lugares onde o espaço essencial do ser humano, a misteriosa procedência do homem e de todas as coisas deixa a sua obscuridade e se mostra em unidade e pertencimento mútuo com o próprio ser humano.

A descoberta da necessidade do inútil dirige o pensamento e também a obra plástica. Desde este direcionamento dá-se a perspectiva que nos permite pensar na intenção e no aceno do nosso título. Chillida que tantos Elogios concedeu com suas obras, compreenderia que a Montanha de Tindaya pudesse ganhar outro nome. Considerando o que ocorreu com a obra Lugar de Encuentros III (1972) em Madrid, conhecida como La sirena varada, acreditamos que a Chillida não lhe causaria espanto, nem tampouco sentiria desvirtuada a concepção que a engendrou caso sua montanha pudesse ser vista como um Elogio do inútil.

\section{REFERÊNCIAS}

AA.VV. Chillida 1948-1998, Museo Nacional Centro de Arte Reina Sofia, 1998.

ALGARÍN COMINO, Mario Arquitecturas excavadas. El proyecto frente a la construcción de espacio, Colección Arquithesis 21, Fundación Caja de Arquitectos, Barcelona, 2006.

BARAÑANO, Kosme. Chillida-Heidegger-Husserl. El concepto de espacio en la filosofía y la plástica del siglo XX, Bilbao, Euskal Herriko Unibersitatea, 1999.

BARAÑANO, K. M. Geometría y tacto: La escultura de Eduardo Chillida 1948-1998. In: AA.VV. Chillida 1948-1998, 1998.

BARAÑANO, Kosme. Heidegger y Chillida. In: BARAÑANO, 1990.

BARAÑANO, Kosme. Symposium Chillida, Bilbao, Universidad del País Vasco, 1990.

CHILLIDA, Eduardo. Escritos, Madrid, La Fabrica Editorial, 2005.

CHILLIDA, Susana. Elogio del horizonte - conversaciones con Eduardo Chillida, Barcelona, Destino, 2003.

CHILLIDA, Eduardo Genios del arte, Susaeta Ediciones, Madrid, 2006.

18 Como propõe Valente, "(la escultura) en Eduardo es un arte de desocupación del espacio" (VALENTE/CALVO SERRALLER, 1996, p.113)

Cadernos Cajuína, V. 6, N. 1, 2021, p. 326-338.

ISSN: 2448-0916 
ESTEBAN, Claude. Chillida, Paris, Maeght, 1971.

FATH, Manfred. Sobre el problema del espacio en Heidegger y Chillida. In: BARAÑANO, 1990.

GROTH, Miles. Arte y vacío: espacio y lugar en Heidegger y Chillida, THÉMATA. Revista de Filosofía, no 57, 2018.

HEIDEGGER, Martin. Aus der Erfahrung des Denkens, GA 13, Frankfurt a.m., V. Klostermann, 1983A.

HEIDEGGER, Martin. Bauen Whonen Denken. In: Vorträge und Aufsätž, GA 7, Frankfurt a.m., Vittorio Klostermann, 2000.

HEIDEGGER, Martin. Begegnungen mit Ortega y Gasset. In: HEIDEGGER, 1983A.

HEIDEGGER, Martin. Der Satzvom Grund, GA 10, Frankfurt a.m, Vittorio Klostermann, 1997.

HEIDEGGER, Martin. Der Ursprung des Kunstwerkes. In Holzwege, GA 5, Frankfurt a.m., Vittorio Klostermann, 1977.

HEIDEGGER, Martin. Die Kunst und der Raum, GA 13, Frankfurt a.m., Vittorio. Klostermann, 1983B.

HEIDEGGER, Martin. Einfubrung in die Metaphysik, GA 40, Frankfurt a.m., Vittorio Klostermann, 1983C.

HEIDEGGER, Martin. Überlieferte Sprache und technische Sprache, St.Gallen, Erker, 1989.

MATTOOS CASTAÑO, Beatriz Eduardo Chillida, arquitecto, Tesis Doctoral, Madrid, Escuela Tecnica Superior de Arquitectura, Universidad Politécnica de Madrid, 2015.

ORTEGA Y GASSET, José "Sobre el especialista y el filósofo". Anejo: en torno al "Coloquio de Darmstadt', 1951, Obras Completas IX, Madrid, Alianza Editorial, 1983.

PINILLA, Ricardo. Los espacios logrados y habitados: Escultura y arquitectura a la luz de la obra de Eduardo Chillida y del pensamiento de Martin Heidegger. In: Arte, Individuo y Sociedad, vol. 14, 2002, pp.269-271.

RABE, Ana M. El Arte y la tierra en Martin Heidegger y Eduardo Chillida. In: Arte, Individuo y Sociedad, vol. 15, 2003, pp. 169-191.

TAUT, B. La corona de la ciudad. In: Escritos Expresionistas, Madrid, Croquis, 1997.

UGALDE, Martin, Hablando con Chillida, Vida y obra, Donostia, Txertoa, 2002.

VALENTE, José.Angel/ CALVO SERRALLER, Francisco. El arte como vacío - Conversación con Eduardo Chillida. Revista de Occidente, junio 1996. 